\title{
Noncompaction of the Left Ventricular Myocardium: A Cause of Syncope in a Young Patient
}

\author{
Deephak Swaminath MD, Ragesh Panikkath MD, Roshni Narayanan MD, Sam Copeland MD
}

\begin{abstract}
Noncompaction of the left ventricular myocardium (LVNC) is a rare cardiomyopathy with a spectrum of clinical presentations. The pathogenesis of this type of cardiomyopathy involves an arrest in the process of compaction during embryonic life. Identification of high risk individuals with this syndrome is challenging; it can cause presentations ranging from an asymptomatic state to malignant ventricular arrhythmias and sudden death. We present a 19-year-old man who presented with syncope and was later diagnosed with left ventricular noncompaction.
\end{abstract}

Key words: cardiomyopathy, echocardiography, noncompaction

\section{INTRODUCTION}

Noncompaction of the left ventricular myocardium (NCLV) is included in the wide spectrum of cardiomyopathies triggered by gene mutations. Left ventricular noncompaction describes a distinct morphological appearance of a thickened, two-layered myocardium with an epicardial compacted layer and a much thicker endocardial noncompacted layer. Over the past 25 years, information about the etiology, embryogenesis of the myocardium, diagnosis, and outcome of LVNC has significantly increased. The World Health Organization/International Society and Federation of Cardiology Task Force on the definition and classification of cardiomyopathies grouped LVNC as an unclassified cardiomyopathy. The American Heart Association has recognized the rapid evolution of molecular genetics in cardiology and classified LVNC as a primary, genetic cardiomyopathy.

Corresponding author: Deephak Swaminath MD Contact Information: deephak.swaminath@ttuhsc.edu DOI: 10.12746/swrccc2013.0103.033

\section{Case Presenttion}

A 19-year-old African American man without any significant past medical history presented with a history of syncope while playing softball. The patient was playing softball; he felt very uneasy during the game and stepped out to drink water. After drinking water he lost consciousness and fell down. He denied any pre-syncopal episodes, nausea, vomiting, palpitation, and profuse sweating. The patient regained consciousness within a few seconds. He experienced two more episodes of loss of consciousness but was sitting on a chair and supported by his friends. He denied drug use, and his urine drug screen was negative. His cardiovascular examination was normal. Cardiac troponin levels were within normal limits. His echocardiogram showed a hypertrabeculated left ventricle with blood flow in the intertrabecular recesses freely communicating with the left ventricular cavity (Figures1,2). The left ventricular systolic function was normal (ejection fraction $65-69 \%$ ). This study satisfied Jenni's criteria for LVNC. A stress echocardiogram showed a mid-cavity gradient of $151 \mathrm{mmHg}$ 
during peak exercise. His telemetry during hospitalization was normal. The patient was discharged with an event monitor and advised to follow up in the electrophysiology clinic. He was also advised to refrain from strenuous activity and was offered screening for his first degree relatives.

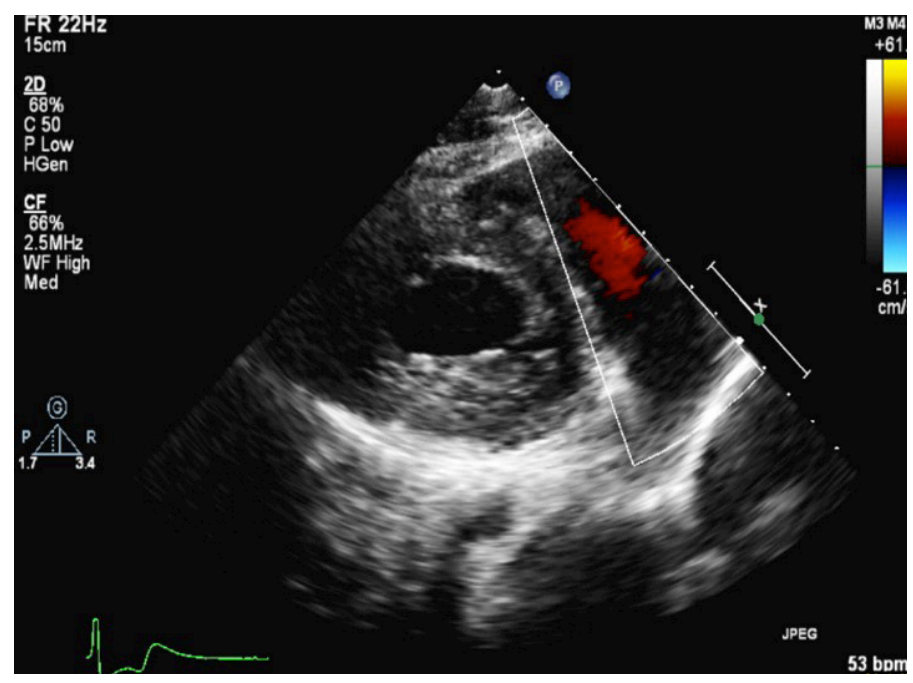

Figure 1. Short axis view of transthoracic echocardiogram showing noncompacted and compacted region of the left ventricle. The noncompacted region was more than twice the compacted region in thickness in diastole.

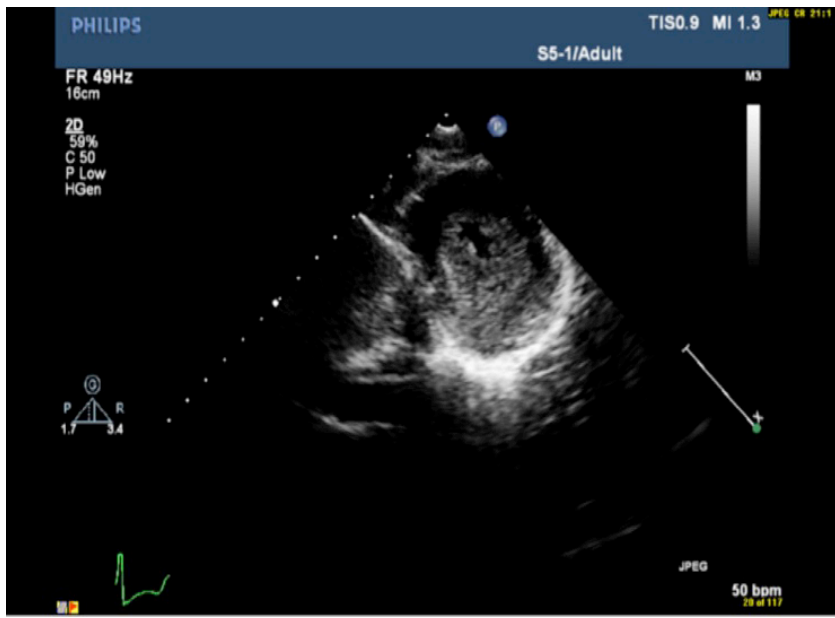

Figure 2. Short axis view of transthoracic echocardiogram showing noncompacted and compacted region of the left ventricle. The noncompacted region was more than twice the compacted region in thickness in both systole and diastole.

\section{Discussion}

The prevalence of LVNC in adults remains uncertain; the incidence of LVNC in the general population has been estimated at $0.05 \%$ to $0.25 \%$ per year. ${ }^{1,2,3}$ LVNC is thought to result from an arrest in endomyocardial morphogenesis during the embryonic period. In early embryonic development, heart muscle is a loose interwoven network of muscle fibers. Compaction of the left ventricular myocardium occurs as part of the normal developmental process in fetal life starting between the 14th and 18th weeks. The failure of this process may result in persistence of a spongy layer on the inner aspect of the myocardium. ${ }^{4,5}$ This may have a genetic basis, but no consistent genetic markers for this condition have been identified. ${ }^{6}$

There is a clear distinction between symptomatic and asymptomatic LVNC. Symptoms include syncope, thromboembolic events, heart failure, and arrhythmias. Symptomatic patients have a dismal prognosis, whereas the asymptomatic patients have a stable course over several years. The frequency of heart failure in symptomatic patients is much higher than the frequency in asymptomatic patients $(61 \%$ vs. $2 \%)$. The incidence of ventricular tachycardia was high $(27 \%)$ in one small Holter study in patients with LVNC. Other studies have reported ventricular arrhythmias in $2-62 \%$ of patients with LVNC. ${ }^{7}$ ECG abnormalities have been reported to be extremely prevalent in children with LVNC. The PR interval, QRS duration, and QTC interval are prolonged in children with LVNC compared to the general population. ${ }^{7}$ LVNC can be diagnosed by echocardiogram and cardiac magnetic resonance imaging. Several criteria have been reported for the diagnosis of LVNC; the Jenni criteria are frequently used. ${ }^{8}$ These criteria require a bi-layered myocardium (thin compacted layer and a thicker noncompacted layer, which is twice the thickness of the compacted layer in end systole). Blood flow in the deep intertrabecular recesses in the noncompacted layer can be demonstrated by color flow on an echocardiogram. Cardiac magnetic resonance imaging can provide an estimate of the mass of the trabeculated portion of the left ventricle, and a mass greater than $20 \%$ of the total LV mass provides a sensitive 
and specific marker for this diagnosis. However, there is no diagnostic gold standard, and the diagnosis can be challenging since LVNC shares many features of dilated and hypertrophic cardiomyopathies.

Medical and surgical treatment is similar to other cardiomyopathies and depends on the presenting clinical manifestations. Since the clinical presentation of LVNC has a wide spectrum of manifestations, each case needs to be approached on an individual basis for management. Treatment is directed by the patient's symptoms and includes evaluation for anticoagulation, management of heart failure, and treatment of arrhythmias. ${ }^{9}$ The frequency of ventricular tachycardia/ fibrillation (38-47\%) and sudden death (13-18\%) reported in adults with this condition is high, although it could be partially attributable to referral bias to tertiary referral hospitals. ${ }^{10}$ Risk stratification methods, including inducibility of VT/VF during electrophysiological studies, correlate poorly with outcomes. The criteria for implantable cardioverter defibrillators in this condition have been the same as those for the general population. ${ }^{10}$ Prophylactic ICD implantation is not recommended in the absence of documented hemodynamically significant ventricular tachycardia. ${ }^{11}$ However, there are no evidence-based guidelines available in the literature to guide in risk stratification and management.

In summary, LVNC is a rare form of cardiomyopathy caused by failure of full maturation of the compacted myocardium. It is usually seen in the pediatric population but is also seen in the adult population. In young patients presenting with syncope and arrhythmias, LVNC should be in the differential diagnosis under cardiomyopathies.

\section{KEYPOINTS}

1. A developmental arrest in the left ventricular myocardium during embryogenesis causes noncompaction.
2. Echocardiograms and MRI imaging can identify this cardiomyopathy.

3. These patients can have syncope, heart failure, and malignant ventricular arrhythmias.

\section{REFERENCES}

1. Oechslin EN, AttenhoferJost CH, Rojas JR, et al. Long-term follow-up of 34 adults with isolated left ventricularnoncompaction: A distinct cardiomyopathywith poor prognosis. $\mathrm{J} \mathrm{Am} \mathrm{Coll}$ Cardiol 2000; 36: 493-500.

2. Ritter M, Oechslin E, Sutsch G, Attenhofer C, Schnider J, Jenni R: Isolated noncompaction of the myocardium in adults. Mayo Clin Proc 1997; 72: 26-31.

3. Petersen SE, Selvanayagam JB, Wiesmann F, Robson MD, Francis JM,Anderson RH, Watkins H, Neubauer S: Left ventricular non-compaction.Insights from cardiovascular magnetic resonanceimaging. J Am Coll Cardiol 200; 46: 101-105.

4. Chin TK, Perloff JK, Williams RG, et al. Isolated noncompaction of leftventricular myocardium. A study of eight cases. Circulation 1990; 82: 507-513.

5. Agmon Y, Connolly HM, Olson LJ, Khandheria BK, Seward JB. Noncompaction of the ventricular myocardium. J Am SocEchocardiogr 1999; 12: 859-863. 
6. Ichida F, Tsubata S, Bowles KR, et al. Novel gene mutations in patients with left ventricular noncompaction or Barth syndrome. Circulation 2001; 103: 1256-1263.

7. Ergul Y, Nisli K, Varkal M A, Oner N, Dursun M, Dindar A, Omeroglu R E. Electrocardiographic findings at initial diagnosis in children with isolated left ventricular noncompaction. Ann NoninvasiveElectrocardiol 2011; 16(2): 184-191.

8. Jenni R, Oechslin E, Schneider J, AttenhoferJost C, Kaufmann PA. Echocardiographic and pathoanatomical characteristics of isolated left ventricular non-compaction: a step towards classification as a distinct cardiomyopathy. Heart 2001; 86(6): 666-671. 9. Nagavalli S, Vacek JL. Approach to incidentally diagnosed isolated ventricular noncompaction of myocardium. South Med $J$ 2010; 103(7): 662-668.

10. Caliskan K, Ujvari B, Bauernfeind T, Theuns DA, Van Domburg R T, Akca F, Jordaens L, Simoons ML,Szili-Torok T.The prevalence of early repolarization in patients with noncompaction cardiomyopathy presenting with malignant ventricular arrhythmias. J Cardiovascular Electrophysiology 2012; 23(9) : 938-944.

11. Paterick TE, Tajik AJ. Left ventricular noncompaction: a diagnostically challenging cardiomyopathy. Circ J 2012; 76(7): 1556-1562. 